\title{
Review on Emission of Radiated Electromagnetic Fields from Train Pantograph Arcing
}

\section{Md Mamun Ur Rashid ${ }^{1 *}$, Tadele Belay Tuli ${ }^{2}$}

${ }^{1}$ National Institute of Textile Engineering and Research (NITER), Dhaka, BANGLADESH

${ }^{2}$ Department of Electromechanical Engineering, Addis Ababa Science and Technology University, ETHIOPIA

*Corresponding Contact:

Email: mamun.rashid.duet@gmail.com

\begin{abstract}
Pantograph arc is one of the most common and yet unavoidable difficulties in electrified railways. During winter the intensity of arcing increases due to ice layer on the overhead catenary wire. In AC traction system, the sinusoidal waveforms of the supply voltage and current distort due to pantograph arcing. It generates both conducted and radiated emission in a wide band. Both the DC component and higher order conducted and radiated emission increases with line speed. The amplitude of the DC voltage shows a wide variation concerning train speed, applied voltage, type of electrical load, the gap between the contact wire and the pantograph and current. In this paper, pantograph arcing and its effects on the railway vehicles are described. Sliding contact between the pantograph contact strips and the catenary contact wire is illustrated with the emphasis on the pantograph arcing. Arc characteristics, formation methods, extinction and resignation of the arc are studied. This paper presents a comprehensive review on pantograph arcing and its effects near radio-based mobile communications and other signaling instruments and some other related areas.
\end{abstract}

Key words

Pantograph, Electromagnetic field, Arcing, Electric Train

\section{INTRODUCTION}

In general, the pantograph is one of the most significant apparatus, elevated on the roof of the electrified railway system which collects electric power through sliding contact with an overhead catenary wire. Due to sliding, contact process generates arcing when the train moves forward and results in electromagnetic radiation emission. This arching is one of the most common and yet unavoidable difficulties in electrified railways. Arcing at the sliding contact between pantograph and overhead catenary wire is observed almost all over the place and cannot be escaped entirely. It is the main source of interference in electric railways and have serious consequences on both railway and nearby non-railway systems. It effects 
radiated interference with the radio communication services and wireless networks and conducted interference with the railway signaling systems, power supplies and nearby grounded structures through its return path (Bormann, D. et al., 2003, Buhrkall, L.,et al., 2005). Radio-based communication systems interrupted due to pantograph arcing as it radiates electromagnetic waves in a wide band (Midya, S. et al., 2009), (P. Pozzobon, et al., 2003). Some researcher proposed two analytical approaches to minimize this problem. Approach one: Identification of nominal air gap between wire and pantograph and replace with an optimal value. Approach two: Maintain pantograph and catenary wire in a vibrant pressure level. This paper presents a review on some experimental research to recognize pantograph arcing and influence of different parameters on it using a research laboratory arrangement. As a drive current collection ability, a pantograph takes electric power from the catenary, and conducts it to electric locomotives and catenary's contact wires are typically made from copper or copper-alloy (TB/T2809-2005).

The best electrical performance has been employed from pure copper or $\mathrm{Cu}$-Ag alloy but it has low tensile strength. On the other side, $\mathrm{Cu}-\mathrm{Mg}$ alloy has the greatest mechanical properties, and its resistivity is relatively high that means poor conductivity and more power losses during run condition. However, it is important to select the pantograph slide plate material which must be able to provide self-lubricating properties. At present, the powder alloy slide plates are widely used in China's railway system. To resolve the drawbacks of pure carbon slide plates such as fast wear-tear and short lifespan, immersed metal carbon slide plates are developed and have been widely used (QIAN Zhongliang,et al., 2003 ). The remainder of the paper is organized as follows. Next section provides a general overview of the parameters effecting the pantograph arcing. Another section states the effects of pantograph arcing. Finally, the scientific findings are concluded.

\section{THEORY}

\section{Parameters effecting the pantograph arcing}

There are two main reasons for pantograph arching. Firstly, varying air gap between pantograph and catenary wire due to mechanical oscillation of the train. Secondly, zigzag motion, when pantograph sliding moves both towards the front and laterally (Angelstam, P., et al., 2013, Midya, S., et al., 2008). The DC component can generate harmonics and may saturate the transformer core, including even harmonics (S. Midya and R. Thottappillil, 2007), (L. Buhrkall, 2005), (E. I. Shobert, 1976). The DC components, overshoots and even harmonics propagate in the whole railway system including the rail tracks, track circuits, rolling stock, other locomotives in the same track, vehicle transformers, sub-station supply transformers etc.

There have been several studies on this electromagnetic interference issues come from pantograph arcing, (B. Tellini, et al., 2001), (T. Konefal, et al., 2002), (S. Brillante, et al., 1998), (R. Giannetti, et al., 2001, J. Allan, et al., 1993, A. Collina, et al., 2005, A. J. Mauriello and J. M. Clarke, 1983, L. Buhrkall, 2005, D. Bormann, et al., 2007) both in the conducted and radiated form. However, most of these researches were in fair weather conditions and radiation measurements were done beside the track. In winter, due to ice/snow layer on the overhead contact wire, the arcing become more intense. This makes the situation even more complex. An Overhead Line (OHL) group was formed to have a detailed and controlled investigation on pantograph arcing within the laboratory produced condition (S. Midya, 2008). The details of the test setup can be found in (D. Bormann, 2003), (Midya, et al., 2009), (Bormann, 2007). It was found that pantograph arcing is a polarity dependent phenomenon 
(D. Bormann, 2003, Midya, et al., 2009). Variation in parameters like line speed, traction current, supply voltage, power factor, zigzag motion, etc. and influence the movement of the arc roots across the overhead contact wire and its polarity dependent nature were also investigated (D. Bormann, 2007). Mechanical oscillations generate the pantograph arcing due to attachment and detachment between the contact wire, and the pantograph in the train. Due to the absence of the lubricating moisture layer and presence of an ice layer on the contact wire the arcing gets enhanced and become more visible in winter.

\section{Pantograph Arcing and associated Frequency Spectrum}

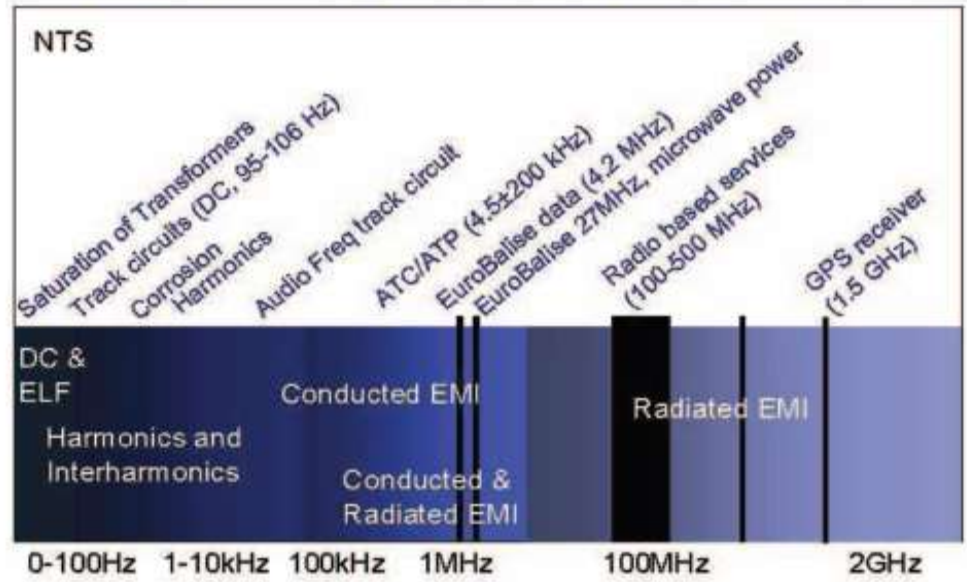

Figure 1: Frequency spectrum of the conducted and radiated emission from pantograph arcing (D. Bormann, 2003)

It has been observed that the voltage drop in the arc is not symmetric in both the half cycles of the power supply. This ice layer acts as a dielectric coating on the contact wire and hampers the proper operation of the sliding contact. For positive contact wire the voltage drop is low and for positive carbon pantograph the voltage drop is large. As a result, a net DC electromotive force is generated over a full AC cycle which acts as a DC source with the carbon and the pantograph as positive pole and the contact wire as negative pole. As experienced by the railway companies and rail administrations, these kind of problems are more severe in winter and cause lot of nuisances and delay in the operation (Bormann, 2007).

In some research works, it was observed by some researchers (L. Buhrkall, 2005) that the net DC voltage generated from the pantograph arcing increases with increasing velocity of the overhead conductor, decreasing arc current, increasing gap between the pantograph and the contact wire. CHEN Song, propose the improvement of the pantograph's current collection performance and electromagnetic noise emission reduction process, a suitable and sufficient contact pressure should be adopted and another is the improvement of the suspension precision of the catenary system in order to minimize the quantity of hard-points (Chen Song, et al., 2009). The normal operation of trains with a pantograph-catenary current collection system has been developed a method for detecting and quantifying the electric arcs. In the pantograph sliding contact process when the actual conductive area becomes relatively small, or the contact resistance relatively high or a larger current flow, the current through the conductive spots will heat the air closed to them then the temperature rose tremendously to a certain extent that the air is ionized, then electrical spark occurs. When train moves it has a reverse and forward shaking which effects on pantograph arcing. 


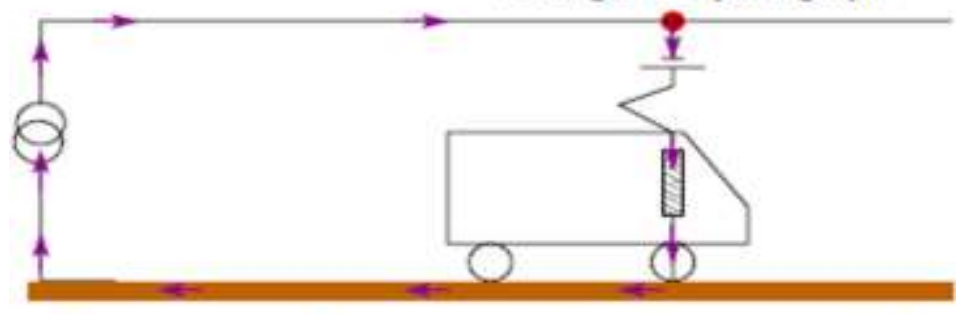

\section{$\rightarrow$ Are generated DC current flow in the entire circuit}

Figure 2: Net DC component generated by the pantograph arcing

\section{Effects of pantograph arcing}

The main problems due to pantograph arcing is generates high frequency signals which effects near radio base stations, mobile and cellular communications, wireless communications, signaling and traffic management systems and some others sensitive train locomotives. Fig. 1 shows an overview of the complete frequency spectrum (starting from $\mathrm{DC}$ and extreme low frequency (ELF) to few $\mathrm{GHz}$ ) that can come out of pantograph arcing and different frequency bands associated with railways.

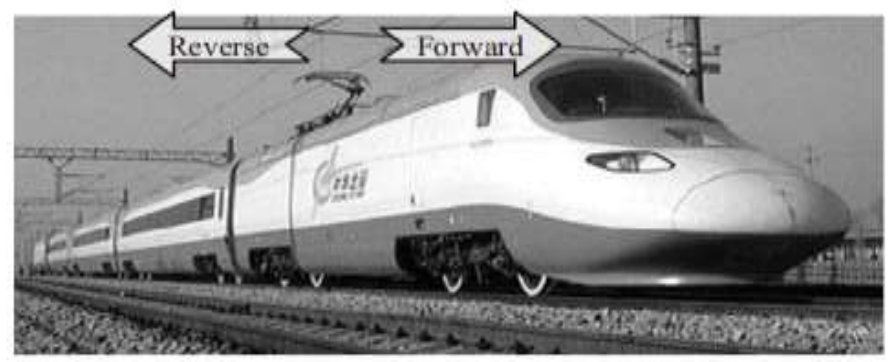

Figure 3: Direction of the Train Running

Figure 3 indicates the direction of the train running and its effects due to pantograph. When train starts it moves forward and shakes laterally by forward and reverse direction and also the pantograph moves with respect to the train speed. If the conductor surface is well polished, then the rate of arcing decreases and less produce the high frequency signals. On the other side, if the conductor surface is very worst then it causes more arcing due to friction with the pantograph.

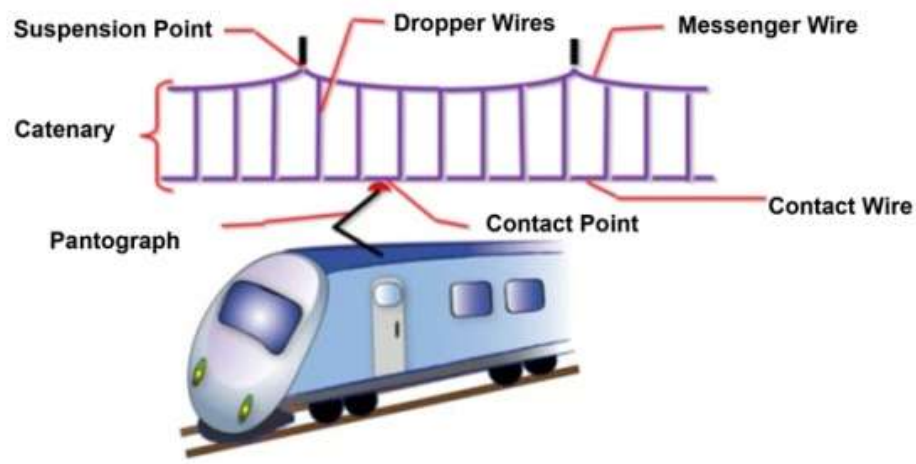

Figure 4: Simple Pantograph and Catenary Wire 
Electrified railways are safe, sustainable, energy efficient, convenient and comfortable for passengers. Amongst the few drawbacks of such trains is the current collection mechanism, generally implemented as a pantograph in mechanical and electrical contact with the overhead line equipment, the catenary wire which elevated on the roof of the train. The Pantograph-Catenary (PAC) system is almost generally used for supplying the vital power to railway electrical trains. Despite offering a balance of cost effectiveness versus reliability, this significant link in the railway power feed chain is also a listed cause of train failure faults. As train speeds increase, the reliability of power collection decreases.

Mechanical models are very useful, for instance: to predict the displacement of the catenary, to predict the contact force, to estimate the component fatigue life, and to analyses the wear induced by the mechanical friction. There is also a need for electrical models to facilitate analysis of (amongst others): power transmission, arcing, and electromagnetic compatibility. Much published work is available on the subject of PAC system modelling and simulation. The pantograph sub-model generally consists of 2 or 3 stages of massspring-damper components. The catenary is a key sub-assembly and its structure is quite complex to model. This task has been carried out by many authors and numerical solutions have been proposed for an infinite or finite dimensional description of the catenary.

An accurately operating pantograph should avoid losses of contact, electric arcing and excessive oscillations of the overhead line and electromagnetic wave emissions. There is general agreement that the design of high- performance (Beadle, A, 1975, Eppinger, S. D., et al., 1988), or servo-actuated pantographs (Galeotti, G., et al., 1993, Balestrino, A., et al., 2000) offers the best possible for the future in terms of cost and optimal current collection. Highquality current collection is categorized by continuous contact between the pantograph and the overhead line. A loss of contact produces break arcs, with the following drawbacks: (a) the arc dissipates a fraction of the energy available for traction; (b) the dissipated energy produces overheating so that the temperature locally increases, causing the overhead wire and the pantograph shoe to deteriorate rapidly.

The occurrence of electrical arcing is more frequent at high speed and in the presence of height variations of the overhead wire (e.g. in the case of tunnels). Various solutions are applied to reduce deterioration due to break arcs and to improve the current collection: 1 . increasing the uplift contact force between the pantograph and the contact wire, at the expense of a reduction of the lifetime of the collector strips and particularly of the contact wire, because of erosive and abrasive wear. 2. A reduction of the pantograph head mass. Unfortunately, the high current transmitted limits such a reduction. 3. A new design of the overhead system. Such an approach only alleviates the problem and it is too expensive where existing systems are to be modified. 4. Applying advanced maintenance techniques (e.g. monitoring the status of the sliding contact).

\section{Conclusions}

In this paper we have reviewed on pantograph arcing, some of its influencing parameters and presence of wide band conducted and radiated emissions. It is shown that pantograph arcing generates a net DC component in the AC traction system, which increase with line speed. It also generates high frequency conducted and radiated emission. As the line speed increases, both the conducted and radiated higher frequency components increases. Because of the electromagnetically noisy and challenging environment, high frequency measurements are difficult and require further investigations. Specially, this paper reviewed the causes of pantograph arcing and its effects in radio base stations and mobile 
or wireless communications sector. Lot of experiments and many of researchers have been continuously working to identify the real reasons and its possible solutions against the problem. Pantograph arcing is a vast problem in electrified railway system and it increases with line speed and the effects is uncontrollable and unpredictable. However, scientists are working over this issues to find a best solution to fix this problem.

\section{REFERENCES}

A. Collina, A. Facchinetti, F. Fossati, and F. Resta, "An application of active control to the collector of an high-speed pantograph: Simulation and laboratory tests," in Proceedings of the 44th IEEE Conference on Decision and Control, 2005 and 2005 European Control Conference. CDC-ECC, Seville, Spain, Dec. 2005, pp. 4602-4609.

A. J. Mauriello and J. M. Clarke, "Measurement and analysis of radiated electromagnetic emissions from rail-transit vehicles," IEEE Trans. Electromagn. Compat., vol. 25, no. 4, pp. 405-411, Nov. 1983.

Angelstam, P., et al., Learning about the history of landscape use for the future: Consequences for ecological and social systems in Swedish Bergslagen. Ambio, 2013. 42(2): p. 146-159.

B. Tellini, M. Macucci, R. Giannetti, and G. A. Antonacci, "Conducted and radiated interference measurements in the line-pantograph system," IEEE Trans. Instrum. Meas., vol. 50, no. 6, pp. 1661-1664, Dec. 2001.

Balestrino, A., Bruno, O., Landi, A. and Sani L. Innovative solutions for overhead catenary pantograph system: wire actuated control and observed contact force. Veh. Syst. Dynamics Int. J., 2000, 33(2), 69-89.

Barmada, Sami, et al. "Clustering techniques applied to a high-speed train pantograph-catenary subsystem for electric arc detection and classification." Proceedings of the Institution of Mechanical Engineers, Part F: Journal of Rail and Rapid Transit 230.1 (2016): 85-96.

Beadle, A. R., Betts, A. I. and Smith, W. R. Pantograph development for high speed. R. Engrs J., 1975, 72-81.

Bormann, D., Origin of DC component in railway line current upon operation with iced-over overhead line: Theory, experimental results and conclusions. ABB Internal Rep. Project: Investigation of DC Current because of Ice On Contact wire", Ref. No: SECRC/PT/TR-2003/038, 2003.

Bormann, Dierk, Surajit Midya, and Rajeev Thottappillil. "DC components in pantograph arcing: Mechanisms and influence of various parameters." Electromagnetic Compatibility, 2007. EMC Zurich 2007. 18th International Zurich Symposium on. IEEE, 2007.

Buhrkall, L., DC components due to ice on the overhead contact wire of AC electrified railways. ELEKTRISCHE BAHNEN-CHARLOTTENBURG THEN BERLIN THEN MUNCHEN-, 2005. 103(8): p. 380.

Chen Song, ShaFei, "Three types of electromagnetic noise between pantograph and catenary," Microwave, Antenna, Propagation and EMC Technologies for Wireless Communications, 2009 3rd IEEE International Symposium on27-29 Oct. 2009, Beijing, China, PP.40 - 43.

D. Bormann, "Origin of DC component in railway line current upon operation with iced-over overhead line: Theory, experimental results and conclusions," ABB Internal Report of the project: Investigation of DC Current because of Ice on Contact wire, Ref. No: SECRC/PT/TR- 2003/038, May 2003.

D. Bormann, S. Midya, and R. Thottappillil, "DC components in pantograph arcing: Mechanisms and influence of various parameters," in Proceedings of 18th International Zurich Symposium on Electromagnetic Compatibility, Munich, Germany, Oct. 2007, pp. 369-372.

E. I. Shobert, "Carbon, graphite and contacts," IEEE Trans. Parts, Hybrids, Packag., vol. PHP-12, no. 6, pp. 62-74, Mar. 1976. 
Eppinger, S. D., O'Connor, D. N., Seering, W. P. and Wormley, D. N. Modeling and experimental evaluation of asymmetric pantograph dynamics. Trans. ASME, J. Dynamics Syst., Measmt Control, 1988, 110, 168-174.

Galeotti, G., Galanti, M., Magrini, S. and Toni, P. Servo actuated railway pantograph for high-speed running with constant contact force. Proc. Instn Mech. Engrs, Part F, Journal of Rail and Rapid Transit, 1993, 207(F1), 37-49.

https:/ / mbellek.blogspot.com/2011/01/ac-lokomotif-diyagram.html

https://www.railwaypro.com/wp/pantograph-catenary-interaction-framework-for-intelligentcontrol/

J. Allan, W. Chan, Z. Shaoz, and B. Mellitt, "Low frequency and radio frequency electromagnetic compatibility for rapid transit railways," in Proceedings of the 5th European Conference on Power Electronics and Applications, Brighton, UK, Sep. 1993, pp. 106-111.

L. Buhrkall, "DC components due to ice on the overhead contact wire of ac electrified railways," Electrische Bahnen, vol. 103, no. 8, pp. 380-389, Aug. 2005.

Midya, S. and R. Thottappillil, An overview of electromagnetic compatibility challenges in European Rail Traffic Management System. Transportation Research Part C: Emerging Technologies, 2008. 16(5): p. 515-534.

Midya, Surajit, et al. "Conducted and radiated emission from pantograph arcing in AC traction system." Power \& Energy Society General Meeting, 2009. PES'09. IEEE. IEEE, 2009.

P. Pozzobon, A. Amendolara, B. Vittorini, U. Henning, R. Schmid, S. Shirran, and S. Ahlstedt, "Electromagnetic compatibility of advanced rail transport signalling," in Proceedings of the World Congress on Railway Research (WCRR), Edinburgh, UK, Oct. 2003, pp. 1250-1263.

QIAN Zhongliang, SHENG Wei, ZHANG Zhimiao, et al. “Development of Carbon Contact Strips and Research Progress in China" [J]. Electric Drive for Locomotives, 2003 (Supplement), pp. 5-8

R. Giannetti, M. Macucci, and B. Tellini, "EMI measurements in line pantograph contact discontinuity in railway transportation systems," in Proceedings of the 11th International Sysmposium on Trends in Electrical Measurement and Instrumentation, IMEKO TC-4, Lisbon, Portugal, Sep. 2001, pp. 25-90.

S. Brillante, P. Ferrari, and P. Pozzobon, "Modelling of electromagnetic emission from catenarypantograph pliding contact," in Proceedings of the International Conference on Computer Aided Design, Manufacture and Operation in The Railway and Other Advanced Mass Transit Systems, Lisbon, Portugal, Sep. 1998, pp. 881-890.

S. Midya and R. Thottappillil, "An overview of electromagnetic compatibility challenges in European rail traffic management system," Transportation Research Part C: Emerging Technologies, 2007, article in press.

S. Midya, "Electromagnetic interference in modern electrified railway systems with emphasis on pantograph arcing," Licentiate Thesis, Uppsala University, May 2008.

T. Konefal, D. A. J. Pearce, C. A. Marshman, and L. M. McCormack, "Potential electromagnetic interference to radio services from railways," Final Report, Mar. 2002.

TB/T2809-2005: Copper and Copper-Alloy Contact Wires for Electric Railway [S]. Ministry of Railways of the People's Republic of China, 2005. 
ISSN: 2409-3629

Online Archive Link: https://abc.us.org/ojs/index.php/ei/issue/archive 